\title{
Biochemical composition and energy content of the mussel Mytilus galloprovincialis of subtidal and rocky shore origin: Influence of environmental variables and source of mussel seed
}

\section{Composición bioquímica y contenido energético del mejillón Mytilus galloprovincialis de origen submareal e intermareal: Influencia de las variables ambientales y de su origen}

\author{
L. Freites \\ M.J. Fernández-Reiriz* \\ U. Labarta
}

Consejo Superior de Investigaciones Científicas

Instituto de Investigaciones Marinas

Eduardo Cabello 6

36208 Vigo, Spain

*E-mail: mjreiriz@iim.csic.es

Recibido en marzo de 2003; aceptado en junio de 2003

\begin{abstract}
The energy content and biochemical composition of seed of the mussel Mytilus galloprovincialis of two distinct origins (subtidal and rocky shore) were compared after both groups were transferred to the water column (subtidal habitat) in the Arousa Ria, NW Spain. The experimental period comprised a total of 228 days. The relative percentages of carbohydrates, glycogen and lipids were significantly higher in the subtidal mussels in the first 15 days, whereas the proteins were significantly higher in the rocky shore mussels during the first 36 days. A multiple regression analysis referred to the same time period showed that the origin of the mussel seed influenced significantly the variance observed in the energy values of all biochemical components (measured in terms of $\mathrm{kJ} \mathrm{mg}^{-1}$ ). In the period between days 50 and 110 , mussel origin only showed a significant effect on the lipid energy content, but in contrast to the previous period, the content was greater in the rocky shore mussels. The multiple regression analysis showed that after 125 days of culture, mussel origin did not influence the variance observed in the energy values of all biochemical components, whereas the ratio chlorophyll $a$ /particulate organic material, temperature and total particulate material influenced significantly the variance observed in the different energy values of all biochemical components. Changes observed in the energy content of carbohydrates and lipids throughout the different periods of this study can be related to catabolismanabolism processes linked mainly to the availability of phytoplanktonic food. Moreover, with regard to lipids, our results suggest that changes were also associated with reproductive activity.
\end{abstract}

Key words: biochemical composition, energy content, Mytilus galloprovincialis, mussel seed, Arousa Ria.

\section{Resumen}

Se compararon el contenido energético y la composición bioquímica de semillas del mejillón Mytilus galloprovincialis de dos orígenes distintos (submareal e intermareal), una vez que ambas semillas fueron colocadas en la columna de agua (hábitat submareal) en la Ría de Arousa, Noroeste de España. El periodo experimental comprendió un total de 228 días. Los porcentajes relativos de glucógeno y lípidos, además del de carbohidratos, fueron significativamente más altos en los mejillones de origen submareal, durante los primeros 8 y 15 días, respectivamente, mientras que en los de origen intermareal, las proteínas fueron significativamente más altas en los primeros 36 días. Durante este mismo periodo, el análisis de regresión múltiple mostró que el origen de los mejillones influyó de significativamente en la varianza observada en los valores energéticos de los diferentes componentes bioquímicos, medidos en términos de $\mathrm{kJ} \mathrm{mg}^{-1}$. Subsecuentemente, entre el día 50 y el 110 , el origen de los mejillones sigue influyendo de manera significativa en el contenido de lípidos, pero en contraste con el periodo anterior, el contenido energético de los mismos fue mayor en los mejillones de origen intermareal. A partir de los 125 días, el análisis de regresión múltiple mostró que el origen de los mejillones no influye en la varianza observada en los equivalentes energéticos de todos los componentes bioquímicos, mientras que la razón clorofila a/MPO, la temperatura y la MPT influyeron significativamente en la varianza observada en los diferentes valores energéticos de todos los componentes bioquímicos. Los cambios observados en la energía contenida en carbohidratos y lípidos, a través de los diferentes periodos de este estudio, pueden estar relacionados con los procesos de anabolismo-catabolismo, ligados a la disponibilidad del alimento fitoplanctónico. Además, con respecto a los lípidos, nuestros resultados sugieren que los cambios observados en los mismos pudieron ser influenciados por la actividad reproductiva.

Palabras clave: composición bioquímica, contenido energético, Mytilus galloprovincialis, semillas de mejillón, Ría de Arousa. 


\section{Introduction}

Parallel studies comparing the biochemical composition of mussel specimens originating from suspended culture in the water column and from the rocky shore intertidal zone are notably lacking. Rodhouse et al. (1984) compared the growth, dry weight and reproductive cycle of Mytilus edulis originating from both suspended culture at $5 \mathrm{~m}$ depth and from the rocky shore zone (13\% air exposure). Under these conditions, the mussels from the suspended culture depended primarily on food of phytoplanktonic origin, and during autumn, their dry weight decreased and they did not show gametogenic development as a consequence of the decrease in phytoplanktonic food. In contrast, during this same autumnal period, the rocky shore mussels utilized a mixture of food dominated by detritus (particulate organic matter), which supplied them with sufficient energy to satisfy basic metabolic requirements as well as gametogenic development.

Other studies have shown that differences in the biochemical composition of mussel populations located in zones with distinct environmental conditions were due to qualitative and/ or quantitative differences in the availability of food of phytoplanktonic origin (Pérez-Camacho et al., 1995; FernándezReiriz et al., 1996; Okumus and Stirling, 1998). With regards to natural populations of mussels of the genus Mytilus spp., annual fluctuations in the different components of the biochemical composition have been related to environmental parameters and the reproductive cycle (Pieters et al., 1979, 1980; Zurburg et al., 1979; De Moreno et al., 1980; Kluytmans et al., 1980; Zandee et al., 1980; Bressan and Marin, 1985; Fernández-Reiriz et al., 1996; Okumus and Stirling, 1998). Accordingly, these studies agreed with the theory established by Bayne (1976), whereby after feeding, a series of metabolic processes come into play, from which the energy obtained from the food could be initially accumulated as reserve tissue and thereafter destined for gametogenesis and/or used in periods of low food availability. This would give as a result a biochemical cycle and, consequently, a reproductive cycle.

An additional aspect that greatly affected the biochemical composition of the intertidal rocky shore mussels is the frequent periods of air exposure, at which times the bivalves were denied a food source. Consequently, the resulting effect would be similar to starvation (Hummel et al., 1989). Bivalves subjected to conditions of nutritive stress have displayed a decrease in glycogen (Bayne, 1973; Gabbott and Bayne, 1973; Riley, 1976). Apart from carbohydrates, specimens of the oyster Crassostrea gigas subjected to food stress over a relatively long period (405 days), showed a decrease of $44 \%$ and $23 \%$ in proteins and lipids, respectively (Whyte et al., 1990).

More recently, Pérez-Camacho et al. (1995) compared growth of mussel seed obtained from different intertidal zones of the Galician coast and from seed collectors placed on raft culture. This study indicated that seed origin had a strong influence on mussel growth, since seeds from collectors showed greater growth rates than those of the rocky shore. This

\section{Introducción}

Existen escasos estudios donde se compare, de forma paralela, la composición bioquímica de mejillones cultivados en suspención en la columna de agua con la de los de la zona intermareal rocosa. Rodhouse et al. (1984) compararon crecimiento, peso seco y ciclo reproductivo de Mytilus edulis provenientes de cultivo suspendido a $5 \mathrm{~m}$ de profundidad y de la zona intermareal rocosa (con un mínimo de 13\% de exposición al aire). Bajo estas condiciones, los mejillones cultivados dependieron principalmente del alimento de origen fitoplanctónico; sin embargo, como consecuencia de la escasa disponibilidad de este alimento durante el otoño, sus pesos secos disminuyeron y no se observó desarrollo gonádico. En contraste, durante este mismo periodo los mejillones de la zona intermareal se alimentaron de una mezcla de alimento resuspendido por el oleaje, compuesto principalmente por detritus (materia orgánica particulada), que les suplió de energía suficiente para satisfacer su metabolismo básico y además les permitió un desarrollo gonádico.

En otros estudios se ha mostrado que las diferencias observadas en la composición bioquímica de algunas poblaciones de mejillones distribuidas en zonas con condiciones ambientales distintas, se debieron a diferencias cualitativas y/o cuantitativas en la disponibilidad del alimento de origen fitoplanctónico (Pérez-Camacho et al., 1995; Fernández-Reiriz et al., 1996; Okumus y Stirling, 1998). En el caso de poblaciones naturales de mejillones del género Mytilus spp., las fluctuaciones anuales ocurridas en sus diferentes componentes bioquímios han sido relacionadas con las variables ambientales y con su ciclo reproductivo (Pieters et al., 1979, 1980; Zurburg et al., 1979; De Moreno et al., 1980; Kluytmans et al., 1980; Zandee et al., 1980; Bressan y Marin, 1985; Fernández-Reiriz et al., 1996; Okumus y Stirling, 1998). Si bien todos estos estudios vinieron a confirmar lo establecido por Bayne (1976) en el sentido de que, una vez adquirido el alimento, entran en juego una serie de procesos metabólicos en los que la energía obtenida del mismo podría ser previamente acumulada como tejido de reserva y posteriormente destinada para la gametogénesis y/o utilizada en periodos de baja disponibilidad del alimento. Todo esto daría como resultado un ciclo bioquímico y con éste, un ciclo reproductivo.

Ahora bien, en el caso de los mejillones distribuidos en la zona intermareal, una de las condiciones que han afectado de manera importante su composición bioquímica son los frecuentes periodos de exposición al aire debido a que, durante los mismos, estos bivalvos no tienen acceso al alimento suspendido en la columna de agua. En consecuencia, estos periodos tendrían un efecto similar a los de inanición (Hummel et al., 1989). En este sentido, bivalvos sometidos a condiciones de estrés nutritivo han mostrado una disminución en sus niveles de glucógeno (Bayne, 1973; Gabbott y Bayne, 1973; Riley, 1976). Además de los carbohidratos, en ejemplares de la ostra Crassostrea gigas que fueron sometidos a estrés alimenticio durante un periodo relativamente largo (405 días), se observó 
difference was attributed to some aspects of the initial state of the collector seed, such as initial greater condition index and previous adaptation to culture conditions under permanent immersion.

The present work is part of a larger research that aims to elucidate what causes the differences observed in the performance of both groups of mussel seed. Two studies have been published about the changes that occurred in the different lipid classes (Freites et al., 2002a) and fatty acid profiles (Freites et al., 2002b) of juvenile populations of subtidal and rocky shore origin of Mytilus galloprovincialis. This study describes the changes that occurred in the biochemical composition (proteins, lipids and carbohydrates) and energetic content of these two seed groups after being transferred to the same habitat (subtidal) in the Arousa Ria, NW Spain.

\section{Material and methods}

\section{Experimental design}

The experimental period extended from 27 November 1995 to 3 July 1996. Individuals used in this study were taken from the rocky shore zone of the Arousa Ria, Spain, and from collector ropes (subtidal environment) suspended from a mussel raft, installed in the same ria. Both groups of seed were from the previous spring-summer spawning and therefore belonged to the same year class. Additionally, the sampling locations for both populations were $2 \mathrm{~km}$ away from each other. At the outset, no significant differences in size and initial mass of the two mussels groups were noted (ANOVA, $P>0.05$ ). The location on the raft, rope density $\left(1.6 \mathrm{~kg} \mathrm{~m}^{-1}\right)$ and depth of culture $(1.5-5.0 \mathrm{~m})$ were identical for both seed groups.

\section{Environmental variables}

Seston and corresponding fractions, TPM (Total Particulate Material) $=$ POM (Particulate Organic Material) + PIM (Particulate Inorganic Material), and particulate volume $\left(\mathrm{mm}^{3}\right)$ were recorded (6 sub-samples) at the same interval depth of the mussel seeds under study. The seston samples were filtered with previously washed Whatman GF/C filters ( 3 times with $10 \mathrm{~mL}$ distilled water) and dried (muffle $450^{\circ} \mathrm{C} / 4 \mathrm{~h}$ ). The filtered material was washed with a solution of ammonium formate $(0.5 \mathrm{M})$ to eliminate salts and dried $\left(110^{\circ} \mathrm{C} / 24 \mathrm{~h}\right)$. The organic component (POM) was determined gravimetrically after sample combustion (muffle $450^{\circ} \mathrm{C} / 4 \mathrm{~h}$ ). The particulate volume was determined with a Coulter Counter Multisizer II. The indicators of nutritional quality $\mathrm{Q}_{1}(\mathrm{POM} / \mathrm{TPM}), \mathrm{Q}_{2}$ (POM/particle volume) and the ratio chl- $a / \mathrm{POM}$ were subsequently calculated. The data characterizing the seston phytoplankton component, expressed as concentration of chl- $a$, temperature ( $\mathrm{T}$ ) and salinity, were provided by the Marine Environment Quality Control Centre at the Ministry of Fisheries, Shell Fisheries and Aquaculture of the Galician Regional Government (Xunta de Galicia). Chlorophyll $a$ was calculated from fluorescence data. una disminución del $44 \%$ y $23 \%$ en proteínas y lípidos, respectivamente (Whyte et al., 1990).

Más recientemente, Pérez-Camacho et al. (1995) compararon el crecimiento de semillas de mejillón obtenidas a partir de diferentes zonas intermareales de las costas de Galicia y colectores colocados en las bateas. En este estudio se observó que el stock u origen de las semillas tenía una marcada influencia sobre el crecimiento de los mejillones, dado que las semillas obtenidas a partir de colectores presentaron mayores tasas de crecimiento que las de los mejillones de la zona intermareal. Dicha diferencia se atribuyó a algunos aspectos del estado inicial de las semillas de colector, tales como mayor índice de condición y una previa adaptación a las condiciones de cultivo bajo inmersión permanente.

El presente estudio forma parte de una investigación más amplia que busca aclarar cuáles son las causas de las diferencias observadas en el rendimiento o desempeño de ambos grupos de semillas. De este modo fueron publicados dos estudios relacionados con los cambios ocurridos en las diferentes clases de lípidos (Freites et al., 2002a) y ácidos grasos (Freites et al., 2002b) en poblaciones de juveniles de origen submareal e intermareal de Mytilus galloprovincialis. En el presente trabajo se describen los cambios ocurridos en la composición bioquímica (proteínas, carbohidratos y lípidos) y el contenido energético de estas dos poblaciones de mejillones, después de haber sido colocados en el mismo ambiente (submareal) de la Ría de Arousa, en el noroeste de España.

\section{Materiales y métodos}

\section{Diseño experimental}

El periodo experimental se llevó a cabo entre el 27 de noviembre de 1995 y el 3 de julio de 1996. Los individuos utilizados en este estudio fueron colectados en la zona rocosa costera de la Ría de Arousa, España, y de colectores suspendidos de una balsa de cultivo instalada en la misma ría. Los dos grupos de juveniles provenían de desoves ocurridos durante el periodo primavera-verano y, por lo tanto, pertenecían a la misma clase anual. Además, ambos sitios se encontraban a 2 $\mathrm{km}$ de distancia entre sí. Al inicio del experimento no se observaron diferencias significativas entre talla y masa inicial de ambos grupos de mejillones (ANOVA, $P>0.05$ ). La localización en la balsa, la densidad $\left(1.6 \mathrm{~kg} \mathrm{~m}^{-1}\right)$ y la profundidad de cultivo $(1.5-5.0 \mathrm{~m})$ fueron idénticos para ambos grupos de mejillones.

\section{Variables ambientales}

Se registraron clorofila $a$, el seston y sus diferentes fracciones, materia total particulada (MTP), materia orgánica particulada (MOP) y materia inorgánica particulada (MPI), además del volumen particulado (seis submuestras en cada caso) a la misma profundidad del cultivo de los mejillones. Las muestras de seston fueron filtradas con filtros Whatman GF/C previamente lavados (tres veces con $10 \mathrm{~mL}$ de agua destilada) 


\section{Treatment of samples}

For each survey, three subsets of mussels $(n=3)$, each comprising 30 individuals, were taken at random from both mussel groups, thus making a total of 90 individuals per mussel group. Each subset came from a different rope, for both mussel groups. The soft tissues of the individuals of each subsample were separated, freeze-dried at $-70^{\circ} \mathrm{C}$ under a vacuum of $0.018 \mathrm{mbar}$, and stored at $-70^{\circ} \mathrm{C}$. Tissues were pulverized using a model 6 Fritsch Pulverisette, and homogenized with water in an ultrasonic vibrator Sonifier 250.

\section{Biochemical composition}

Quantification of proteins was carried out following the methodology described by Lowry et al. (1951), after hydrolysis of the sample with $\mathrm{NaOH} 0.5 \mathrm{~N}$ at $30^{\circ} \mathrm{C}$ for $24 \mathrm{~h}$. Bovine albumin (Sigma) was used as a standard and underwent the same hydrolysis treatment.

Carbohydrates were measured by the phenolsulphur reaction as proposed by Strickland and Parsons (1968), with glucose as a standard. The same method was also used to determine glycogen after precipitation with $100 \%$ ethanol.

Lipids were first extracted with chloroform:methanol (1:2), and after centrifugation (3246 G), the precipitate was again extracted with chloroform:methanol (2:1). Both supernatants were then washed with chloroform:methanol:water (8:4:3), as described previously by Fernández-Reiriz et al. (1998). The solvents contain $0.05 \%$ butylated hydroxytoluene (BHT). Total lipids were determined gravimetrically by evaporating the solvent of $200 \mu \mathrm{L}$ of purified extract onto pre-weighed aluminium plates on a slide warmer $\left(60-80^{\circ} \mathrm{C}\right)$ (Rouser et al., 1967).

The energy conversion factors used for protein, carbohydrate and lipid, expressed as $\mathrm{kJ} \mathrm{g}^{-1}$, were taken from Beukema and De Bruin (1979).

\section{Statistical analysis}

Differences in the biochemical components between subtidal and rocky shore mussel seeds were analyzed by a oneway analysis of variance (ANOVA). Relative percentages of biochemical components were previously arcsine transformed (Zar, 1984), and the Bartlett test of homogeneity of variance was applied to the data.

To study the influence of environmental parameters on the variation of the energy equivalents of the different biochemical components, in collector and rocky shore mussel seeds, a multivariate Stepwise regression was performed. In this analysis, the source of mussel seed "origin" factor is attributed to a qualitative factor (dummy), in such a way that the collector mussels are assigned a value of 0 (zero) and the rocky shore mussels a value of 1 (one). The significance level employed for the regression analysis was $95 \%$ (Zar, 1984). y secados $\left(450^{\circ} \mathrm{C} / 4 \mathrm{~h}\right)$. El material filtrado fue lavado con una solución de formiato de amonio $(0.5 \mathrm{M})$ para eliminar las sales y luego secado a $110^{\circ} \mathrm{C} / 24 \mathrm{~h}$. El componente orgánico (POM) fue determinado gravimétricamente mediante la combustión previa de las muestras (mufla a $450^{\circ} \mathrm{C} / 4 \mathrm{~h}$ ). El volumen empaquetado fue determinado por medio de un contador de partículas Coulter Multisizer II. Con estos datos se calcularon los indicadores de calidad del alimento $\mathrm{Q}_{1}(\mathrm{POM} / \mathrm{TPM}), \mathrm{Q}_{2}$ $\left(\mathrm{POM} \mathrm{mm}{ }^{-3}\right)$ y razón clorofila $a / \mathrm{POM}\left(\mu \mathrm{g} \mathrm{mg}^{-1}\right)$ que caracterizan al mismo. Los datos del componente fitoplanctónico del seston, expresado como concentración de la clorofila $a$, la temperatura y la salinidad, fueron suministrados por el Centro de Control del Medio Marino de la Consellería de Pesca, Marisqueo e Acuicultura (Xunta de Galicia).

\section{Tratamiento de las muestras}

En los muestreos fueron tomadas al azar tres submuestras de 30 individuos de los mejillones de origen submareal e intermareal, conformando un total de 90 individuos por cada grupo de mejillones. Para ambos grupos de mejillones, las submuestras procedían de cuerdas diferentes. Los tejidos blandos de los individuos de cada submuestra fueron separados, colocados en tres envases y después liofilizados y almacenados a $-70^{\circ} \mathrm{C}$. Previo al desarrollo de los diferentes análisis bioquímicos, los tejidos de los mejillones fueron pulverizados mediante el uso de un Pulverisette 6 (Fritsch) y homogeneizados mediante un Sonicador ultrasónico 250.

\section{Composición bioquímica}

La cuantificación de proteínas se realizó siguiendo la metodología descrita por Lowry et al. (1951), previa hidrólisis de la muestra con $\mathrm{NaOH} 0.5 \mathrm{~N}$ a $30^{\circ} \mathrm{C}$ durante $24 \mathrm{~h}$. Se empleó albúmina de bovino (Sigma) como estándar, luego de ser sometida al mismo tratamiento de hidrólisis.

Los carbohidratos fueron medidos mediante la reacción de fenol-sulfuro (Strickland y Parsons, 1968), utilizando como estándar glucosa. El mismo método fue empleado para determinar glucógeno, con la única diferencia, que previamente este compuesto fue precipitado con etanol al 100\%.

Los lípidos fueron extraídos primeramente con una solución metanol-cloroformo 2:1. Después se centrifugaron (3246 G) para obtener un primer sobrenadante. El precipitado fue sometido a una nueva extracción con una solución metanolcloroformo 1:2. Ambos sobrenadantes fueron lavados con una solución con proporciones 8:4:3 de cloroformo-metanol-agua a la manera descrita previamente por Fernández-Reiriz et al. (1998). Como solvente fue empleada una solución al $0.05 \%$ de butilato hidroxitolueno (BHT). Los lípidos fueron determinados de manera gravimétrica, depositando $200 \mu \mathrm{L}$ del extracto purificado en envases de aluminio de peso conocido, que a su vez fueron colocados en una plancha a una temperatura entre $60^{\circ} \mathrm{C}$ y $80^{\circ} \mathrm{C}$. Luego de la evaporación del solvente estos envases fueron pesados, obteniendo de esta manera el peso del extracto lipídico (Rouser et al., 1967). 


\section{Results}

\section{Environmental variables}

With the advance of winter, a sustained decrease in water temperature was observed until reaching a minimum of $12.5^{\circ} \mathrm{C}$ (fig. 1a). Thereafter, a sustained increase of temperature was noted during spring, until peaking in June $\left(16.3^{\circ} \mathrm{C}\right)$. Chlorophyll $a$ presented relatively low values during the winter (fig. 1b), with minimal concentrations $\left(0.61 \mu \mathrm{g} \mathrm{L} \mathrm{L}^{-1}\right)$; however, chlorophyll $a$ increases shortly thereafter, reaching maximum values during spring $\left(3.71 \mu \mathrm{g} \mathrm{L}^{-1}\right)$. With regards to seston, between late November and early February (fig. 1c) a series of fluctuations occurred, with maximum values for TPM, POM and PIM in early January $\left(2.56,1.00\right.$ and $1.29 \mu \mathrm{g} \mathrm{L}^{-1}$, respectively). Following these increased concentrations, two new increments in TPM and POM were observed in February (1.34 and $0.57 \mathrm{mg} \mathrm{L}^{-1}$, respectively) and in April (1.38 and $0.64 \mathrm{mg} \mathrm{L}^{-1}$, respectively). Similar events to those described for seston also occur in the particulate volume (fig. 1d), with an emphatic peak in April $\left(1.66 \mathrm{~mm}^{3}\right)$. Accordingly, three peaks can be observed in the particulate volume, the first corresponding to the seston maximum at the start of January, and the following two peaks corresponding to those observed in chlorophyll $a$ during spring. Regarding food quality, two clear periods can be discerned in $\mathrm{Q}_{2}$ ( $\mathrm{POM} /$ particle volume) (fig. 1e). The first interval between late November and midFebruary (winter) was characterized by values generally above 0.6 , and the second in spring, had values generally below 0.6 . These two clearly defined intervals are reflected in the changing chlorophyll $a / \mathrm{POM}$ ratio (fig. 1f).

\section{Biochemical composition of mussels of both origins}

With regards to percentage organic material in the individual mussels of subtidal and rocky shore origin (table 1), no significant differences were observed (ANOVA, $P>0.05$ ) throughout the experimental period. The relative percentages of carbohydrates, glycogen and lipids were significantly higher in the subtidal mussels (ANOVA, $P<0.05,0.001$ and 0.05 , respectively), whereas proteins were significantly higher in the rocky shore mussels (ANOVA, $P<0.01$ ). These differences were maintained for the first 8 days (glycogen and lipids), 15 days (carbohydrates), and 36 days (proteins) after initiation of the experiment. From day 50 to the end of the experiment, no significant differences were observed (ANOVA, $P>0.05$ ) in the relative percentages of any of the aforementioned biochemical components (table 1).

\section{Energy content of subtidal and rocky shore mussels}

The biochemical composition, expressed in terms of energetic contents $\left(\mathrm{kJ} \mathrm{mg}^{-1}\right)$, allows equations to be calculated that relate the changes that occur in proteins, carbohydrates, lipids and total organic material (fig. $2 \mathrm{a}-\mathrm{d}$ ) of both groups of mussels
Los equivalentes energéticos empleados para la conversión de los datos de proteínas, lípidos y carbohidratos, y expresados como kJ g ${ }^{-1}$, fueron tomados de Beukema y De Bruin (1979).

\section{Análisis estadísticos}

Los datos de los componentes bioquímicos de las semillas de los mejillones de origen submareal e intermareal fueron analizados mediante la aplicación de un análisis de varianza de una vía (ANOVAI). La homogeneidad de la varianza de los datos fue comprobada mediante el test de Bartlett. En el caso de los porcentajes relativos de los componentes bioquímicos, cuando no cumplieron con la homogeneidad exigida, éstos fueron previamente transformados al arcoseno (Zar, 1984).

Para estimar la influencia de las variables ambientales sobre las variaciones de los equivalentes energéticos de los diferentes componentes bioquímicos de ambos grupos mejillones se empleó un análisis de regresión múltiple Stepwise. En este análisis, al factor "origen" le fue asignado un valor cualitativo (dummy), de tal manera que a los mejillones de submareal les correspondió el 0 (cero) y a los de intermareal el 1 (uno). El nivel de significancia empleado en el análisis de regresión fue del 95\% (Zar, 1984).

\section{Resultados}

\section{Variables ambientales}

A medida que el invierno transcurrió se observó una disminución sostenida de la temperatura del agua hasta alcanzar sus valores mínimos $\left(12.5^{\circ} \mathrm{C}\right)$ (fig. 1a). Posteriormente se observó un incremento gradual y sostenido de la temperatura durante la primavera, hasta alcanzar un valor máximo de $16.3^{\circ} \mathrm{C}$ en junio. La clorofila $a$ presentó valores bajos, durante el invierno (fig. 1b), con una concentración mínima de $0.61 \mu \mathrm{L}^{-1}$, y posteriormente se incrementó hasta alcanzar un máximo valor de $3.71 \mu \mathrm{g} \mathrm{L}^{-1}$ durante la primavera. Con respecto al seston, esta variable mostró algunas fluctuaciones entre finales de noviembre y principios de febrero (fig. 1c), sobresaliendo la ocurrida al inicio de enero, con valores máximos de MPT, MPO y MPI de 2.56, 1.00 y $1.29 \mu \mathrm{g} \mathrm{L}^{-1}$, respectivamente. Posteriormente, se observaron dos nuevos incrementos de MPT y MPO en febrero, de 1.34 y $0.57 \mathrm{mg} \mathrm{L}^{-1}$, y en abril, de 1.38 y $0.64 \mathrm{mg} \mathrm{L}^{-1}$, respectivamente. Similares eventos a los descritos para el seston ocurrieron en el volumen particulado (fig. 1d). Consecuentemente, tres picos pueden ser observados en el volumen particulado, el primero coincidió con el máximo observado en el seston a comienzos de enero, mientras que los dos picos siguientes coincidieron con los máximos valores observados de clorofila $a$ en la primavera, y un valor máximo en abril $(1.6 \mathrm{~mm})$. En la calidad del alimento $\left(\mathrm{Q}_{2}\right)$ se observaron dos periodos (fig. 1e). El primero, ocurrido entre finales de noviembre y mediados de febrero (invierno), 

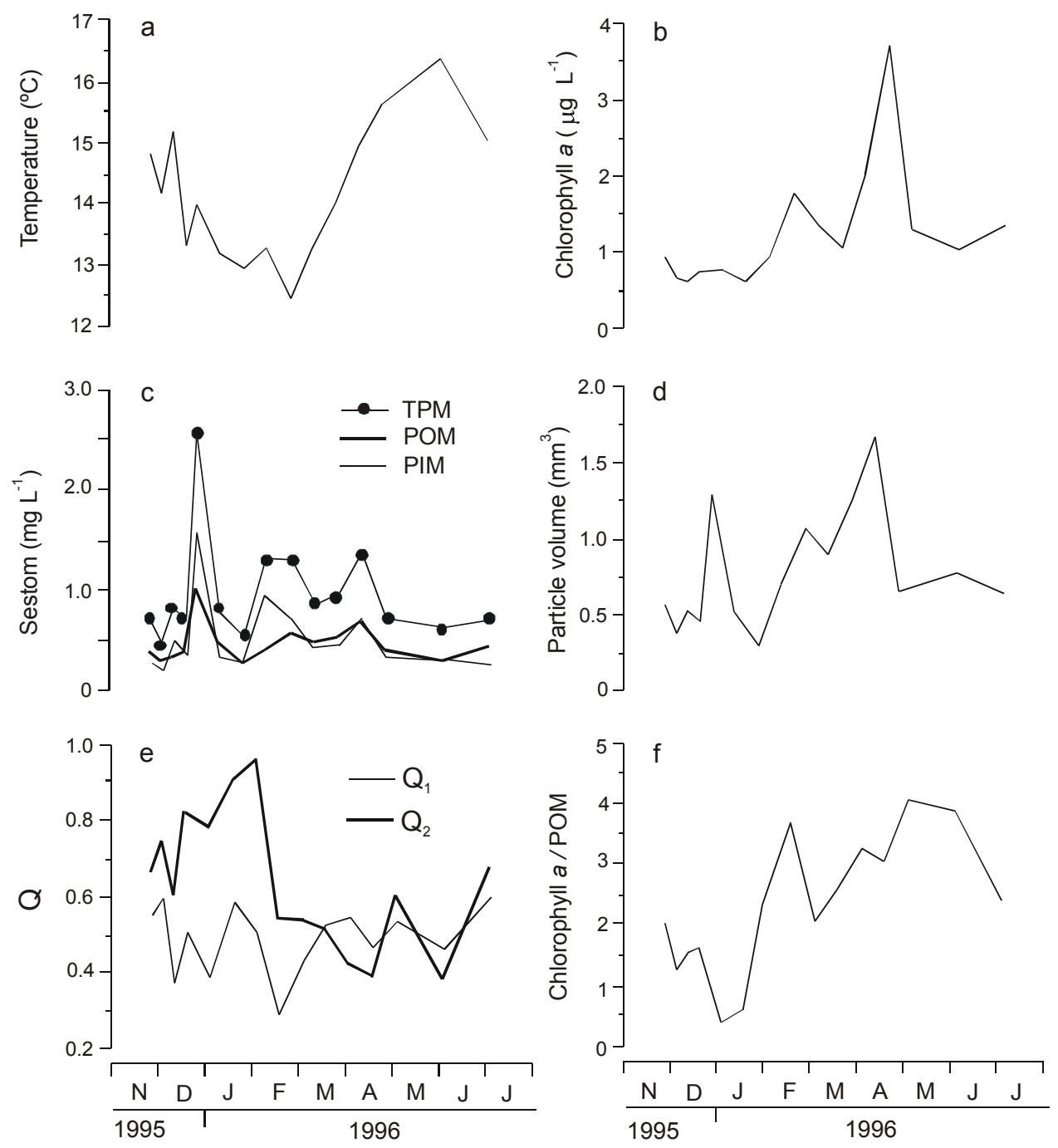

Figure 1. Fluctuations of environmental parameters over the experimental period: (a) temperature, (b) chlorophyll $a$, (c) seston (TPM $=$ total particulate material, $P O M=$ particulate organic material and $P I M=$ particulate inorganic material), (d) particulate volume, $(e)$ food quality $\left(Q_{1}=P O M / T P M\right.$ and $Q_{2}=P O M /$ particle vol. $^{-1}$ ), and (f) ratio chlorophyll a/POM.

Figura 1. Fluctuaciones de los parámetros ambientales ocurridos durante el periodo experimental: (a) temperatura, (b) clorofila a, (c) seston (TPM, POM y $P I M)$, (d) volumen particulado, (e) calidad de alimento $\left(Q_{1}\right.$ y $\left.Q_{2}\right)$, y (f) razón clorofila a/POM.

throughout the experimental culture. The best fit of protein and carbohydrate energy content (fig. 2a-b) for the mussel groups is a quadratic equation (second degree polynomial), whereas the energy from lipids and total organic material is fitted by a third degree polynomial relationship (fig. 2c-d).

For the detailed analysis of the variability in energy content of the different biochemical components and total organic material, taking into account the data of the environmental variables, the experimental period was divided into three periods: winter, transitional and spring-summer. The same temporal criterion was employed for the multiple regression analysis (Stepwise) described below, with the aim of elucidating the influence of environmental parameters and source of mussel seed (origin) on the evolution of the energy content generated from the various biochemical components. con valores mayores a 0.6 , y el segundo en primavera, con valores menores a 0.6. Estos dos periodos variaron de manera inversamente proporcional a los valores de la razón clorofila $a$ / MPO (fig. 1f).

\section{Composición bioquímica de los mejillones de ambos origenes}

Con respecto al porcentaje de materia orgánica de los mejillones de origen submareal e intermareal (tabla 1), no fueron observadas diferencias significativas entre las mismas (ANOVA, $P>0.05$ ) a lo largo de todo el periodo experimental. Al inicio del periodo experimental, los porcentajes relativos ( $\%$ materia orgánica) de los carbohidratos, glucógeno y lípidos (tabla 1) fueron significativamente más altos en los 


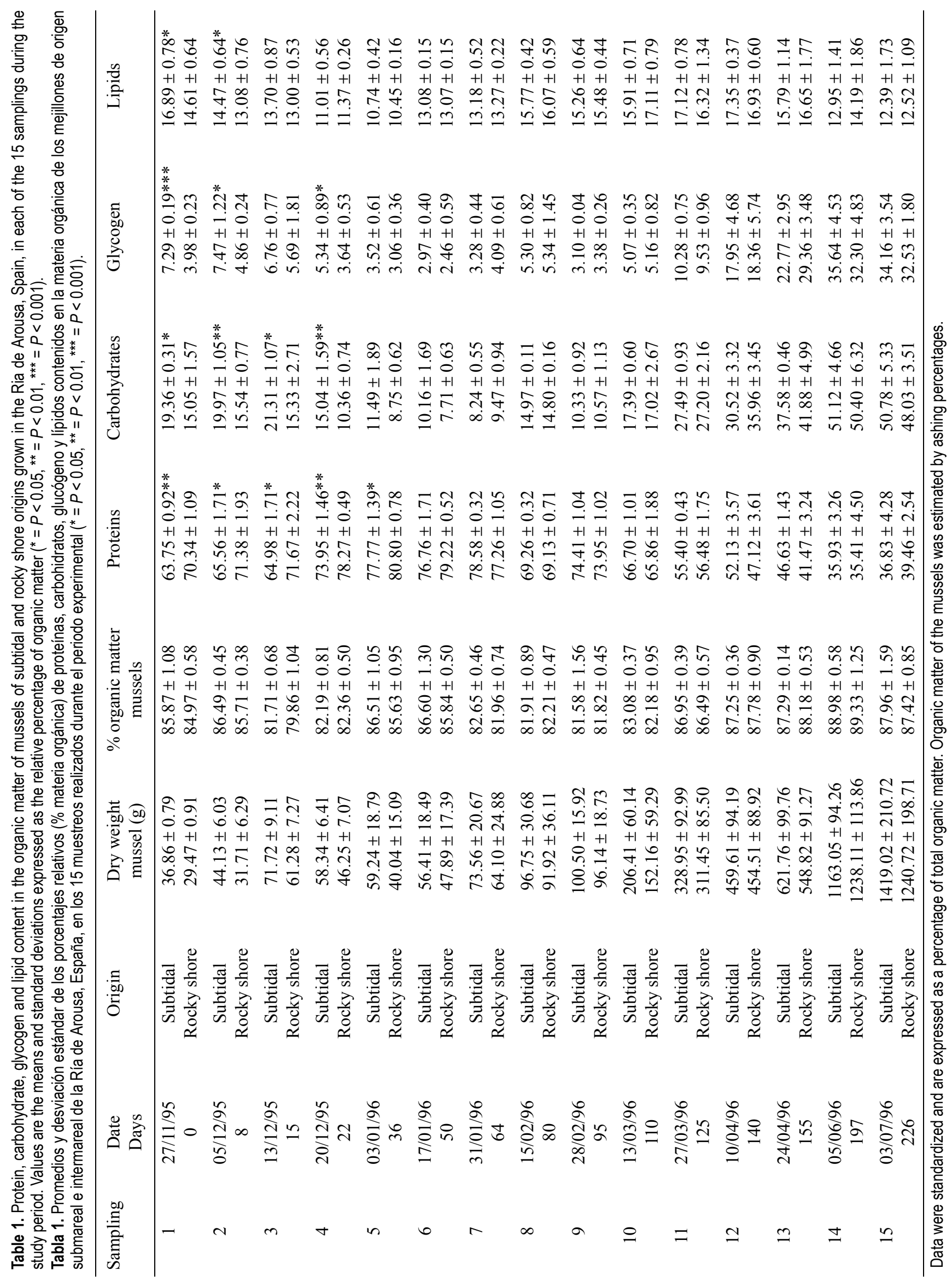




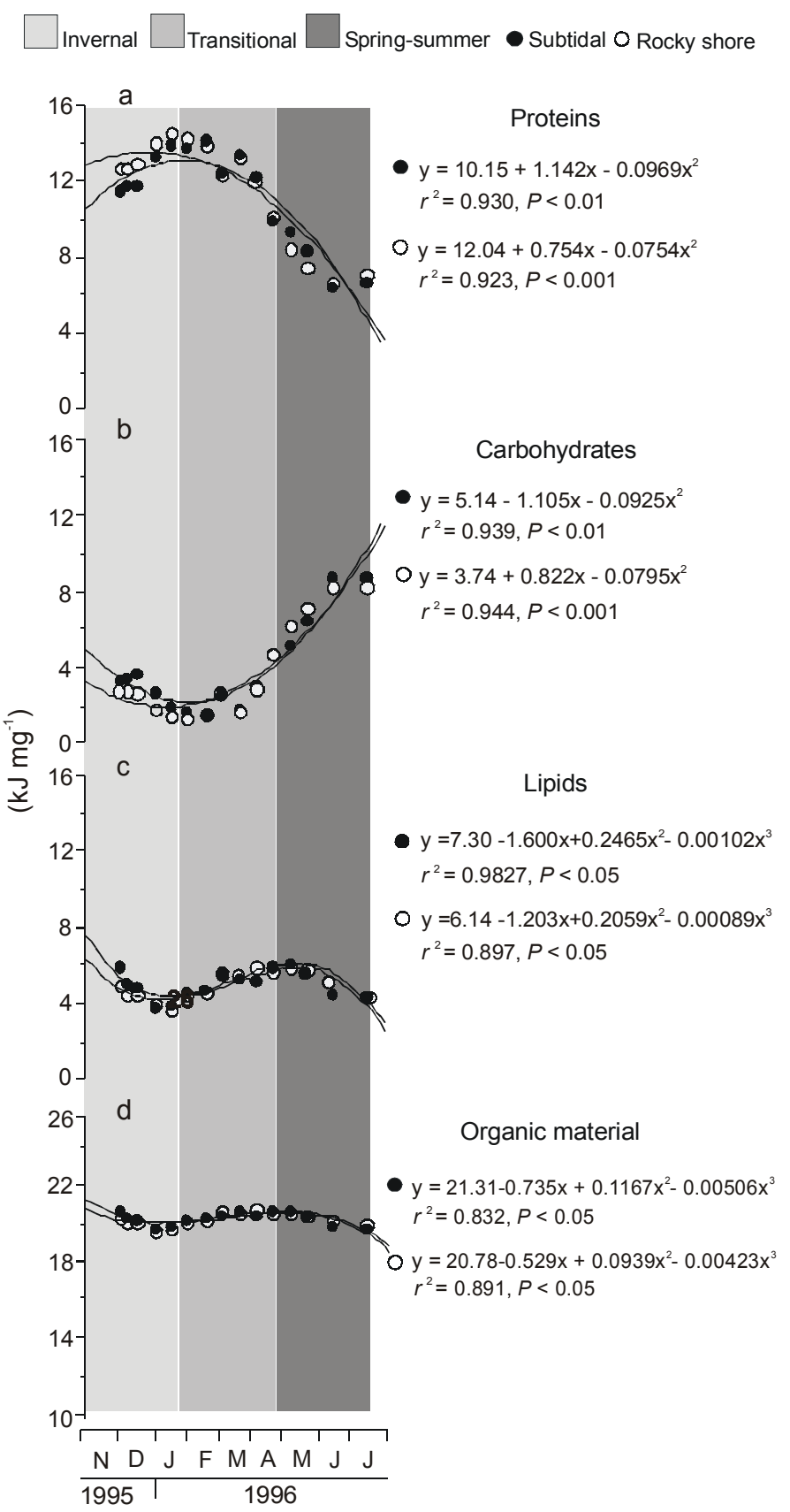

Figure 2. Curves, equations and respective fit of the energy content $\left(\mathrm{kJ} \mathrm{mg}^{-1}\right)$ of (a) proteins, (b) carbohydrates, (c) lipids and (d) organic material of mussel seeds of Mytilus galloprovincialis.

Figura 2. Curvas, ecuaciones y los respectivos ajustes de los contenidos energéticos $\left(\mathrm{kJ} \mathrm{mg}^{-1}\right)$ de las (a) proteínas, (b) carbohidratos, (c) lípidos y (d) materia orgánica de las semillas del mejillón Mytilus galloprovincialis.

\section{Winter period (relatively low phytoplanktonic food availability)}

This period corresponds to the interval between the initial sampling (day 0) and the 5th sampling (day 36). An increment of the protein energy contribution of 2.52 and $1.78 \mathrm{~kJ} \mathrm{mg}^{-1}$ $(21.99 \%$ and $14.01 \%)$ was observed in both the subtidal and mejillones de origen submareal (ANOVA, $P<0.05,0.001 \mathrm{y}$ 0.05 , respectivamente), mientras que las proteínas fueron significativamente más altas en los individuos de origen intermareal (ANOVA, $P<0.01$ ). Dichas diferencias se mantuvieron hasta los 8 días (glucógeno y lípidos), 15 días (carbohidratos) y 36 días (proteínas) de iniciado el periodo experimental. A partir de los 50 días y hasta el final del mismo, no se observaron diferencias significativas (ANOVA, $P>0.05$ ) en los porcentajes relativos de ninguno de los componentes bioquímicos antes mencionados (tabla 1).

\section{Energética de los mejillones de origen submareal e intermareal}

La composición bioquímica, expresada en términos de contenidos energéticos $\left(\mathrm{kJ} \mathrm{mg}^{-1}\right)$, nos permitió establecer las ecuaciones que representan los cambios ocurridos en proteínas, carbohidratos y lípidos, además de materia orgánica total (fig. 2a-d) de ambas poblaciones de mejillones juveniles, durante el periodo experimental. Los mejores ajustes se obtuvieron en la energía contenida en proteínas y carbohidratos, con ecuaciones cuadráticas polinomiales de segundo grado (fig. 2a-b), mientras que para la energía contenida en lípidos y materia orgánica total, el mejor ajuste correspondió con ecuaciones polinomiales de tercer grado (fig. $2 \mathrm{c}-\mathrm{d}$ ).

Tomando como base los datos de las variables ambientales, donde fueron identificados los periodos invernal, transicional y primavera-verano, se procedió a analizar detalladamente los cambios ocurrido en la energía de los diferentes componentes bioquímicos y de la materia orgánica total. Además, se empleo el mismo criterio temporal para la realización del análisis de regresión múltiple (Stepwise), con el objetivo de mostrar la posible influencia de las variables ambientales sobre la evolución observada en los equivalentes energéticos de proteínas, carbohidratos y lípidos.

\section{Periodo invernal (baja disponibilidad de alimento de origen fitoplanctónico)}

Este periodo abarcó entre el muestreo inicial (día 0) y el muestreo 5 (día 36). Durante el mismo se observó un incremento de la energía contenida en las proteínas de los mejillones de submareal e intermareal del orden de $2.52 \mathrm{~kJ} \mathrm{mg}^{-1}$ (21.99\%) y $1.78 \mathrm{~kJ} \mathrm{mg}^{-1}(14.01 \%)$, respectivamente (tabla 2 ). En contraste, durante este mismo periodo, se observó una disminución de la energía contenida en los carbohidratos del orden del $-1.40 \mathrm{y}-1.04 \mathrm{~kJ} \mathrm{mg}^{-1}(-42.05 \% \mathrm{y}-40.84 \%)$, y en los lípidos de -2.06 y $-1.36 \mathrm{~kJ} \mathrm{mg}-1(-34.80 \%$ y $-27.10 \%)$ en mejillones submareales e intermareales, respectivamente. De esta manera, las pérdidas observadas en la energía contenida en carbohidratos y lípidos superan a la energía contenida en las proteínas. Consecuentemente, se observó una pérdida energética de -0.93 y $-0.61 \mathrm{~kJ} \mathrm{mg}^{-1}(-4.49 \%$ y $-3.00 \%)$ en la materia orgánica de ambos grupos de mejillones, respectivamente (tabla 2). 
rocky shore mussels, respectively (table 2). In contrast, during this same period, there was a deficit in carbohydrate energy of -1.40 and $-1.04 \mathrm{~kJ} \mathrm{mg}^{-1}(-42.05 \%$ and $-40.84 \%)$, and in lipid energy of -2.06 and $-1.36 \mathrm{~kJ} \mathrm{mg}^{-1}(-34.80 \%$ and $-27.10 \%)$ for the subtidal and rocky shore mussels, respectively. In this way, the parallel loss observed in the carbohydrate and lipid energy was greater than the contribution observed from proteins. Consequently, a total energy loss of the organic material was observed of -0.93 and $-0.61 \mathrm{~kJ} \mathrm{mg}^{-1}(-4.49 \%$ and $-3.00 \%)$ for the subtidal and rocky shore mussels, respectively (table 2 ).

\section{Transitional period (average phytoplanktonic food availability)}

This period corresponds to the interval between the 6th sampling (day 50) and the 10th sampling (day 110, table 2). In contrast to the winter situation, there was a loss of -1.63 and $-2.46 \mathrm{~kJ} \mathrm{mg}^{-1}(-11.79 \%$ and $-17.20 \%)$ of the energy
Periodo transicional (disponibilidad media de alimento de origen fitoplanctónico)

Este periodo abarcó del muestreo 6 (día 50) al muestreo 10 (día 110, tabla 2). A diferencia de lo ocurrido en el invernal, durante este periodo comienza una disminución de la energía contenida en las proteínas de los mejillones de origen submareal e intermareal, del orden de -1.63 y $-2.46 \mathrm{~kJ} \mathrm{mg}^{-1}$ $(-11.79 \%$ y $-17.20 \%)$, respectivamente. En contraste, se observó un incremento de 1.24 y $1.59 \mathrm{~kJ} \mathrm{mg}^{-1}(71.13 \%$ y $119.65 \%$ ) en la energía contenida en los carbohidratos, y de 0.64 y $1.55 \mathrm{~kJ} \mathrm{mg}^{-1}(13.95 \%$ y $34.75 \%)$ en la contenida en los lípidos, respectivamente. Así, la energía acumulada en estos dos últimos componentes superó la disminución observada en las proteínas, lo que resultó en un incremento de 0.25 y $0.67 \mathrm{~kJ} \mathrm{mg}^{-1}(1.23 \%$ y $3.34 \%)$ en la energía contenida en la materia orgánica, respectivamente.

Table 2. Energy content and energy differential shown by the subtidal and rocky shore mussels at the end of the three periods established: winter, transitional and spring-summer.

Tabla 2. Contenido energético y el diferencial de energía mostrados por los mejillones de origen submareal e intermareal, al final de los periodos invernal, transicional y primavera-verano.

\begin{tabular}{|c|c|c|c|c|c|c|}
\hline \multirow[t]{2}{*}{ Period } & \multirow[t]{2}{*}{ Component } & \multirow[t]{2}{*}{ Origin } & \multicolumn{2}{|c|}{$\begin{array}{l}\text { Energy content } \\
\qquad\left(\mathrm{kJ} \mathrm{mg}^{-1}\right)\end{array}$} & \multicolumn{2}{|c|}{ Energy differential } \\
\hline & & & Initial & Final & $\mathrm{kJ} \mathrm{mg}^{-1}$ & $\%$ \\
\hline \multirow[t]{7}{*}{ Winter } & Proteins & Subtidal & 11.476 & 13.999 & 2.524 & 21.99 \\
\hline & & Rocky shore & 12.755 & 14.543 & 1.788 & 14.01 \\
\hline & Carbohydrates & $\begin{array}{l}\text { Subtidal } \\
\text { Rocky shore }\end{array}$ & $\begin{array}{l}3.323 \\
2.539\end{array}$ & $\begin{array}{l}1.925 \\
1.502\end{array}$ & $\begin{array}{l}-1.398 \\
-1.037\end{array}$ & $\begin{array}{l}-42.05 \\
-40.84\end{array}$ \\
\hline & Lipids & Subtidal & 5.909 & 3.852 & -2.057 & -34.80 \\
\hline & & Rocky shore & 5.019 & 3.658 & -1.360 & -27.10 \\
\hline & Organic material & Subtidal & 20.707 & 19.777 & -0.930 & -4.49 \\
\hline & & Rocky shore & 20.313 & 19.703 & -0.610 & -3.00 \\
\hline \multirow[t]{8}{*}{ Transitional } & Proteins & Subtidal & 13.816 & 12.187 & -1.630 & -11.79 \\
\hline & & Rocky shore & 14.319 & 11.855 & -2.464 & -17.20 \\
\hline & Carbohydrates & Subtidal & 1.744 & 2.984 & 1.240 & 71.13 \\
\hline & & Rocky shore & 1.330 & 2.921 & 1.591 & 119.65 \\
\hline & Lipids & Subtidal & 4.578 & 5.217 & 0.639 & 13.95 \\
\hline & & Rocky shore & 4.445 & 5.990 & 1.545 & 34.75 \\
\hline & Organic material & Subtidal & 20.138 & 20.388 & 0.250 & 1.23 \\
\hline & & Rocky shore & 20.094 & 20.766 & 0.672 & 3.34 \\
\hline \multirow[t]{8}{*}{ Spring-summer } & Proteins & Subtidal & 9.970 & 6.629 & -3.342 & -33.52 \\
\hline & & Rocky shore & 10.167 & 7.102 & -3.064 & -30.14 \\
\hline & Carbohydrates & Subtidal & 4.718 & 8.715 & 3.997 & 84.73 \\
\hline & & Rocky shore & 4.688 & 8.241 & 3.574 & 76.56 \\
\hline & Lipids & Subtidal & 5.990 & 4.335 & -1.655 & -27.62 \\
\hline & & Rocky shore & 5.712 & 4.381 & -1.330 & -23.29 \\
\hline & Organic material & Subtidal & 20.679 & 19.679 & -0.999 & -4.83 \\
\hline & & Rocky shore & 20.546 & 19.725 & -0.821 & -3.99 \\
\hline
\end{tabular}


contributed by the proteins of the subtidal and rocky shore mussels, respectively. On the other hand, a gain of 1.24 and $1.59 \mathrm{~kJ} \mathrm{mg}^{-1}(71.13 \%$ and $119.65 \%)$ was observed in the energy obtained from carbohydrates, and up to 0.64 and $1.55 \mathrm{~kJ} \mathrm{mg}^{-1}(13.95 \%$ and $34.75 \%)$ from the lipids, respectively. Accordingly, the energy storage in these latter compounds is greater in this period than the observed loss in proteins, which results in an increase in the energy storage in the organic material of 0.25 and $0.67 \mathrm{~kJ} \mathrm{mg}^{-1}(1.23 \%$ and $3.34 \%$ ), respectively.

\section{Spring-summer period (relatively high phytoplanktonic food availability)}

This period corresponds to the interval between the 11th sampling (day 125) and the 15th sampling (day 226, table 2). The loss of energy from protein accelerates in the subtidal and rocky shore mussels, judging by the observed values of -3.34 and $-3.06 \mathrm{~kJ} \mathrm{mg}^{-1}(-33.52 \%$ and $-30.14 \%)$, respectively. The loss of energy from the lipids was -1.65 and $-1.33 \mathrm{~kJ} \mathrm{mg}^{-1}$ $(-27.3 \%$ and $-22.5 \%)$, respectively (see fig. $2 \mathrm{c})$. In contrast, the energy storage from carbohydrates for the subtidal and rocky shore mussels shows a marked gain of 3.99 and $3.57 \mathrm{~kJ} \mathrm{mg}^{-1}$ (84.73\% and $76.56 \%$ ), respectively, with regard to the previous period. In this way, the combination of both energy losses (proteins and lipids) is greater than the energy gain from the carbohydrates, the consequence being an energy loss of the total organic material observed at the end of the study period, of the order -0.99 and $-0.82 \mathrm{~kJ} \mathrm{mg}^{-1}(-4.83 \%$ and $-3.99 \%)$, respectively.

\section{Influence of mussel origin and environmental parameters on energy content evolution}

\section{Winter period}

The Stepwise multiple regression analysis applied to the winter period, from late November to early January (table 3), showed that the TPM contribution explained the greatest percentage of the variance observed in the energy content of the proteins and carbohydrates $(57.2 \%$ and $43.7 \%)$, whereas chlorophyll $a / \mathrm{POM}$ contributed to explain the greatest percentage of lipids and organic material $(61.8 \%$ and $59.2 \%$, respectively). With the exception of the energy contained within the organic material, the "origin" term increased the explanation of variance of the protein, carbohydrate and lipid energy equivalents up to $78.1 \%, 85.8 \%$ and $79.0 \%$, respectively, with a negative coefficient for the energy content of carbohydrates and lipids. This is evidence of the higher energy content of subtidal mussels.

\section{Transitional period}

During the period between mid-January and mid-March, TPM alone explained more than $40 \%$ of the variance of the protein, carbohydrate, lipid and organic material energy
Periodo primavera-verano (alta disponibilidad de alimento de origen fitoplanctónico)

Este periodo abarcó del muestreo 11 (día 125) al muestreo 15 (día 226, tabla 2). Se pudo observar que los equivalentes energéticos de las proteínas presentaron una rápida disminución, tanto en los mejillones de origen submareal como en los de intermareal, a juzgar por sus respectivos valores de -3.34 y $-3.06 \mathrm{~kJ} \mathrm{mg}^{-1}(-33.52 \%$ y $-30.14 \%)$. La caída en los lípidos fue de $-1.65 \mathrm{y}-1.33 \mathrm{~kJ} \mathrm{mg}^{-1}(-27.3 \%$ y $-22.5 \%)$, respectivamente (ver fig. 2c). En contraste, los valores energéticos de los carbohidratos de los mejillones de origen submareal e intermareal, mostraron un marcado incremento de 3.99 y $3.57 \mathrm{~kJ} \mathrm{mg}^{-1}$ $(84.73 \%$ y $76.56 \%)$, respectivamente, en relación al observado en el periodo anterior. La conjunción de las disminuciones en proteínas y lípidos superan al incremento observado en los valores energéticos de los carbohidratos. En consecuencia, al final del período de estudio fueron observadas disminuciones en la energía contenida en la materia orgánica total del orden de -0.99 y $-0.82 \mathrm{~kJ} \mathrm{mg}^{-1}(-4.83 \%$ y $-3.99 \%)$, respectivamente.

\section{Influencia del origen de los mejillones y de las variables ambientales sobre la evolución de los equivalentes energéticos}

\section{Periodo invernal}

El análisis de regresión múltiple por etapas aplicado al periodo comprendido entre finales de noviembre y principios de enero (invernal, tabla 3), mostró que la MPT aportó los mayores porcentajes de explicación de la varianza observada en los contenidos energéticos de proteínas y carbohidratos $(57.2 \%$ y $43.7 \%)$, mientras que la razón clorofila $a / \mathrm{MPO}$ aportó los mayores porcentajes de explicación de los lípidos y la materia orgánica $(61.8 \%$ y $59.2 \%$, respectivamente). Por otro lado, con excepción de la energía contenida en la materia orgánica, el término "origen" incrementó la explicación de la varianza de la energía contenida en proteínas, carbohidratos y lípidos, hasta un $78.1 \%, 85.8 \%$ y $79.0 \%$, respectivamente, siendo su coeficiente negativo en los contenidos energéticos de carbohidratos y lípidos. Esto último evidencia que los mejillones de submareal presentaron contenidos energéticos más altos que los de intermareal.

\section{Periodo transicional}

Durante el periodo comprendido entre mediados de enero y marzo (transicional), la MPT explica por sí sola, porcentajes mayores al $40 \%$ de la varianza observada en los contenidos energéticos de proteínas, carbohidratos, lípidos y materia orgánica de ambos grupos de mejillones (tabla 4). Además de ésta, la razón clorofila $a / \mathrm{MPO}$ participa en la explicación de la varianza observada en las energías contenidas en lípidos y materia orgánica, elevándolas hasta un 55.9 y $50.5 \%$, respectivamente. Por otro lado, el "origen" de los mejillones continua 
Table 3. Stepwise multiple regression of the energetic values of proteins, carbohydrates, lipids and total organic material of seed of Mytilus galloprovincialis of subtidal and rocky shore origins with the environmental variables total particulate material (TPM), ratio chlorophyll a/particulate organic material (chl-a/POM) and temperature $(\mathrm{T})$, for the winter period.

Tabla 3. Análisis de regresión múltiple por etapas (Stepwise) de los equivalentes energéticos de las proteínas, carbohidratos, lípidos y materia orgánica total, de las semillas del mejillón Mytilus galloprovincialis de origen submareal e intermareal y las variables ambientales material particulado total (TPM), la razón clorofila a/material orgánico particulado (chl-a/POM) y temperatura $(\mathrm{T})$, para el periodo invernal.

\begin{tabular}{|c|c|c|c|c|c|}
\hline Parameters & Coefficients & SE & $F$-ratio & $r^{2}$ & $P$ \\
\hline Constant & 23.168 & & & & \\
\hline TPM & 0.564 & 0.414 & 46.111 & 0.572 & $<0.001$ \\
\hline Origin & 0.948 & 0.458 & 69.048 & 0.781 & $<0.001$ \\
\hline $\mathrm{T}$ & -0.758 & -0.579 & 90.434 & 0.921 & $<0.001$ \\
\hline
\end{tabular}

\section{Carbohydrates $\left(\mathrm{kJ} \mathrm{mg}^{-1}\right)$}

\section{Constant}

TPM

$\mathrm{T}$

Origin

$$
-3.040
$$

$-0.411$

0.434

$-0.745$

$$
-0.433
$$

0.476

$-0.517$
28.098

33.863

48.875
0.437

$<0.001$

0.704

$<0.001$

0.858

$<0.001$

$r^{2}=0.858 ; n=30 ; F_{3.26}=52.285 ; P<0.001$

\section{Lipids $\left(\mathrm{kJ} \mathrm{mg}^{-1}\right)$}

Constant

$-4.442$

Chl-a/POM

0.471

0.374

14.737

0.618

$<0.001$

$\mathrm{T}$

0.569

0.643

43.600

0.737

$<0.001$

Origin

$-0.322$

$-0.230$

6.574

0.790

$<0.05$

$r^{2}=0.815 ; n=30 ; F_{3.26}=32.625 ; P<0.001$

Total organic material $\left(\mathrm{kJ} \mathrm{mg}^{-1}\right)$

Constant

Chl- $a$ /POM

$\mathrm{T}$

$r^{2}=0.707 ; n=30 ; F_{2.27}=32.571 ; P<0.001$
16.023

0.210

0.252

0.367

10.575

0.592

$<0.01$

0.629

31.026

0.707

$<0.001$ content of both mussel groups (table 4). Furthermore, chlorophyll $a / \mathrm{POM}$ participated in the explanation of the variance in energy content in the lipids and organic material, raising them to $55.9 \%$ and $50.5 \%$, respectively. Additionally, the mussel origin continued to participate in the explanation of the variance observed in lipid energy content and subsequently for the organic material during this second period. In both cases the coefficients are positive, thus illustrating the higher energy contents of the rocky shore mussels.

\section{Spring-summer period}

Between the end of March and the beginning of July (spring, table 5), TPM was the parameter contributing the contribuyendo de manera significativa a la explicación de la varianza observada en los contenidos energéticos de los lípidos, y pasó a participar de manera significativa en la explicación de los contenidos energéticos de la materia orgánica durante este segundo periodo, pero en ambos casos sus coeficientes son positivos, lo que indicaría que los mejillones de intermareal presentaron mayores contenidos energéticos de este componente bioquímico.

\section{Periodo primavera-verano}

Durante el periodo comprendido entre finales de marzo y principios de julio, que incluye la primavera (tabla 5), la MPT fue el parámetro que explicó en mayor porcentaje las varianzas 
Table 4. Stepwise multiple regression of the energetic values of proteins, carbohydrates, lipids and total organic material of seed of Mytilus galloprovincialis of subtidal and rocky shore origins with the environmental variables total particulate material (TPM), ratio chlorophyll a/particulate organic material (chl-a/POM) and temperature $(T)$, for the transitional period.

Tabla 4. Análisis de regresión múltiple por etapas (Stepwise) de los equivalentes energéticos de las proteínas, carbohidratos, lípidos y materia orgánica total, de las semillas del mejillón Mytilus galloprovincialis de origen submareal e intermareal y las variables ambientales material particulado total (TPM), la razón clorofila a/material orgánico particulado (chl-a/POM) y temperatura (T), para el periodo transicional.

\begin{tabular}{|c|c|c|c|c|c|}
\hline Parameters & Coefficients & $\mathrm{SE}$ & $F$-ratio & $r^{2}$ & $P$ \\
\hline Constant & 0.927 & & & & \\
\hline ТPM & -2.303 & -0.731 & 51.983 & 0.526 & $<0.001$ \\
\hline $\mathrm{T}$ & 1.061 & 0.443 & 19.102 & 0.722 & $<0.001$ \\
\hline \multicolumn{6}{|c|}{ Carbohydrates $\left(\mathrm{kJ} \mathrm{mg}^{-1}\right)$} \\
\hline Constant & 11.133 & & & & \\
\hline TPM & 1.566 & 0.698 & 41.750 & 0.479 & $<0.001$ \\
\hline $\mathrm{T}$ & -0.772 & -0.453 & 17.557 & 0.685 & $<0.001$ \\
\hline
\end{tabular}

\section{Lipids $\left(\mathrm{kJ} \mathrm{mg}^{-1}\right)$}

Constant

TPM

Chl-a/POM

$\mathrm{T}$

Origin

\subsection{1}

1.019

0.176

$-0.447$

0.307

0.534

18.335

0.446

$<0.001$

0.298

$-0.308$

0.262

5.662

0.559

$<0.05$

7.697

0.628

$<0.01$

5.644

0.696

$r^{2}=0.696 ; n=30 ; F_{4.25}=14.340 ; P<0.001$

Total organic material $\left(\mathrm{kJ} \mathrm{mg}^{-1}\right)$

Constant

TPM

Chl-a/POM

$\mathrm{T}$

Origin

\subsection{2}

0.427

0.080

$-0.180$

0.152

$r^{2}=0.662 ; n=30 ; F_{4.25}=12.220 ; P<0.001$ greatest percentage explanation of the variability in energy content of the carbohydrates, lipids and organic material (31.8\% and $35.0 \%$, respectively). Conversely, temperature attained the greatest percentage explanation of the variance in protein energy equivalents $(41.2 \%)$. Furthermore, temperature displayed a negative coefficient and is thus evidence of an inverse relationship between this parameter and protein energy. Moreover, chlorophyll $a / \mathrm{POM}$ also participated in the explanation of the variance in the energy contained within the proteins, carbohydrates, lipids and organic material in both mussel groups, raising the respective explanations to $79.2 \%, 78.5 \%$, $55.8 \%$ and $55.8 \%$ (table 5 ). observadas en la energía contenida en carbohidratos, lípidos y materia orgánica $(31.8 \%$ y $35.0 \%$, respectivamente), mientras que la temperatura fue el parámetro ambiental que alcanzó el mayor porcentaje de explicación de la varianza observada en la energía contenida en las proteínas $(41.2 \%)$. En este último caso la temperatura mostró un coeficiente negativo, lo que evidenció la relación inversa entre este parámetro y la energía contenida en las proteínas. Además de estos parámetros, la razón clorofila $a / \mathrm{MPO}$ también contribuyó a la explicación de la varianza observada en la energía contenida en proteínas, carbohidratos, lípidos y materia orgánica de ambos grupos de mejillones, elevando sus respectivas contribuciones hasta un $79.2 \%, 78.5 \%, 55.8 \%$ y $55.8 \%$, respectivamente (tabla 5). 
The correlation between the environmental parameters, mussel origin and energy values of proteins, carbohydrates, lipids and organic material described above were all significant $(P<0.05)($ tables $3,4,5)$.

\section{Discussion}

The results from the present study show that at the start of the experiment the subtidal and rocky shore mussels presented significant differences in relative percentage (\% organic material) of all the integrals of the biochemical composition studied (proteins, carbohydrates, glycogen and lipids). These differences were maintained at least over the first eight days and concur with previous studies, which show that the biochemical
Todas las contribuciones descritas de las diferentes variables ambientales, el origen de los mejillones y los diferentes valores energéticos de proteínas, carbohidratos, lípidos y materia orgánica, fueron significativas $(P<0.05)$ (tablas $3,4,5)$.

\section{Discusión}

Los resultados obtenidos en el presente estudio muestran que al inicio del periodo experimental los mejillones de origen submareal e intermareal presentaron diferencias significativas en los niveles de todos los componentes bioquímicos estudiados (proteínas, carbohidratos, glucógeno y lípidos), y que las mismas se mantuvieron, en el menor de los casos, hasta ocho días después de iniciado el mismo. Estas diferencias

Table 5. Stepwise multiple regression of the energetic values of proteins, carbohydrates, lipids and total organic material of seed of Mytilus galloprovincialis of subtidal and rocky shore origins with the environmental variables total particulate material (TPM), ratio chlorophyll a/particulate organic material (chl-a/POM) and temperature $(T)$, for the spring-summer period.

Tabla 5. Análisis de regresión múltiple por etapas (Stepwise) de los equivalentes energéticos de las proteínas, carbohidratos, lípidos y materia orgánica total, de las semillas del mejillón Mytilus galloprovincialis de origen submareal e intermareal y las variables ambientales material particulado total (TPM), la razón clorofila a/material orgánico particulado (chl-a/POM) y temperatura (T), para el periodo primavera-verano.

\begin{tabular}{|c|c|c|c|c|c|}
\hline Parameters & Coefficients & SE & $F$-ratio & $r^{2}$ & $P$ \\
\hline \multicolumn{6}{|c|}{ Proteins $\left(\mathrm{kJ} \mathrm{mg}^{-1}\right)$} \\
\hline Constant & 41.623 & & & & \\
\hline $\mathrm{T}$ & -2.800 & -0.888 & 49.215 & 0.412 & -0.001 \\
\hline TPM & 2.087 & 0.394 & 15.328 & 0.670 & $<0.001$ \\
\hline Chl- $a / \mathrm{POM}$ & 1.590 & 0.658 & 31.480 & 0.792 & $<0.001$ \\
\hline \multicolumn{6}{|c|}{$r^{2}=0.792 ; n=30 ; F_{3.26}=33.088 ; P<0.001$} \\
\hline \multicolumn{6}{|c|}{ Carbohydrates $\left(\mathrm{kJ} \mathrm{mg}^{-1}\right)$} \\
\hline Constant & -27.233 & & & & \\
\hline $\mathrm{T}$ & -2.800 & 0.461 & 20.261 & 0.401 & $<0.001$ \\
\hline ТPM & -2.969 & -0.811 & 39.547 & 0.497 & $<0.001$ \\
\hline Chl- $a / \mathrm{POM}$ & 1.590 & -0.703 & 34.646 & 0.785 & $<0.001$ \\
\hline \multicolumn{6}{|c|}{$r^{2}=0.785 ; n=30 ; F_{3.26}=31.550 ; P<0.001$} \\
\hline \multicolumn{6}{|c|}{ Lipids $\left(\mathrm{kJ} \mathrm{mg}^{-1}\right)$} \\
\hline Constant & 9.606 & & & & \\
\hline TPM & 1.731 & 0.603 & 19.668 & 0.318 & $<0.001$ \\
\hline Chl- $a / \mathrm{POM}$ & 0.932 & 0.712 & 20.184 & 0.558 & $<0.001$ \\
\hline $\mathrm{T}$ & -0.611 & -0.357 & 4.371 & 0.621 & $<0.05$ \\
\hline \multicolumn{6}{|c|}{$r^{2}=0.621 ; n=30 ; F_{3.26}=14.213 ; P<0.001$} \\
\hline \multicolumn{6}{|c|}{ Total organic material $\left(\mathrm{kJ} \mathrm{mg}^{-1}\right)$} \\
\hline Constant & 24.001 & & & & \\
\hline ТРM & 0.980 & 0.593 & 21.153 & 0.350 & $<0.001$ \\
\hline Chl- $a / \mathrm{POM}$ & 0.549 & 0.729 & 23.531 & 0.558 & $<0.001$ \\
\hline $\mathrm{T}$ & -0.442 & -0.450 & 7.869 & 0.659 & $<0.01$ \\
\hline
\end{tabular}


composition of the bivalves clearly reflects the conditions of the habitat where they develop (Whyte et al., 1990; Napolitano et al., 1992; Fernández-Reiriz et al., 1996; Okumus and Stirling, 1998).

The rationale for the differences between mussel groups is probably the contrasting conditions of mussel seed development. Frequent periods of air exposure exercise a greater influence on the energy reserves of rocky shore mussels due to the absence of food. Accordingly, a decrease in tissue weight has been observed in mussel specimens subjected to periods of starvation as a result of catabolism of other energy reserves such as lipids and proteins (Hummel et al., 1989). Furthermore, during periods of air exposure, rocky shore mussels do not have access to the dissolved oxygen in seawater, at which times they rely on anaerobic metabolism (glycolysis) as the principal source of energy (De Zwaan and Mathieu, 1992). The upshot is a decrease in glycogen reserves, a phenomenon observed elsewhere in other species of bivalve molluscs affected by air exposure (Gäde, 1975; Bayne et al., 1982; Gabbott, 1983; Hummel et al., 1989).

In view of the fact that no data were obtained on the reproductive cycle of the mussel seed in the present study, variations observed in the biochemical composition cannot be related directly with this aspect. Notwithstanding, some insight can be gained based on three studies carried out in the Galician rias related to the reproductive cycle of this species, namely, a description of the gametogenic cycle and energy reserves by Ferrán et al. (1990), and detailed studies of the gametogenic cycle described by Villalba (1995) and Cáceres-Martínez and Figueras (1998). Hence, the observed increase in energy equivalents of protein from November to January (winter) could be interpreted as a process of active gametogenesis, given that Villalba (1995) and Cáceres-Martínez and Figueras (1998) observed a high percentage of specimens in this stage of the reproductive cycle in the Arousa and Vigo Rias. In contrast, the decrease in energy contribution of carbohydrate and lipid reserves would probably be related to the low availability of phytoplanktonic food from November to January (see fig. 1b). The latter agrees with the results of Zandee et al. (1980) and Okumus and Stirling (1998), who also noted a decrease in carbohydrate and lipid content during winter in the mussel M. edulis.

The rise in energy generated from carbohydrates and lipids over the transitional period between winter and spring is probably due to increasing availability of phytoplanktonic food (see fig. 1b). Furthermore, in view of the fact that Villalba (1995) and Cáceres-Martínez and Figueras (1998) observed a high percentage of specimens with their gametes maturing between January and April, a parallel process of accumulation of lipid reserves in the gametes cannot be ruled out. Accumulation of lipid reserves in the mussel M. galloprovincialis has been recorded previously by Lubet et al. (1983, 1986) during oocycte maturation.

From April onwards a simultaneous decrease in energy content in protein and lipid was observed in both mussel concuerdan con las de estudios previos en los que se ha observado que la composición bioquímica de los bivalvos refleja claramente las condiciones del hábitat donde se desarrollaron (Whyte et al., 1990; Napolitano et al., 1992; Fernández-Reiriz et al., 1996; Okumus y Stirling, 1998).

La causa de tales diferencias probablemente tenga su origen en las diferentes condiciones en las que se desarrollaron previamente ambos grupos de mejillones. En el caso de los mejillones de origen intermareal, los frecuentes periodos de exposición al aire es una de las condiciones que ejercen mayor influencia sobre sus reservas energéticas debido a que estos implican periodos de ausencia de alimento. Así, en los ejemplares de mejillones sometidos a condiciones de inanición se ha podido observar una disminución del peso de los tejidos como resultado del catabolismo de otras reservas energéticas tales como lípidos y proteínas (Hummel et al., 1989). Además, durante los periodos de exposición al aire los mejillones tampoco tienen a su disposición el oxígeno contenido en el agua de mar, lo que los hace depender del metabolismo anaerobio (glucólisis) como fuente principal de energía (De Zwaan y Mathieu, 1992). Esto último se reflejaría en una disminución de las reservas de glucógeno, fenómeno que ha sido también observado en otras especies de moluscos bivalvos afectados por periodos de exposición al aire (Gäde, 1975; Bayne et al., 1982; Gabbott, 1983; Hummel et al., 1989).

Debido a que en el presente trabajo no se realizaron observaciones del ciclo reproductivo de los mejillones bajo estudio, los cambios observados en la composición bioquímica de los mismos no podrían ser relacionados con este aspecto. No obstante, es posible hacer algunas de estas interpretaciones apoyándonos en tres estudios realizados en la rías gallegas y relacionados con el ciclo reproductivo de esta especie: la descripción del ciclo gametogénico y de reservas energéticas del mejillón M. galloprovincialis, realizado por Ferrán et al. (1990), y los estudios detallados de su ciclo gametogénico, descrito por Villalba (1995) y Cáceres-Martínez y Figueras (1998). De esta manera, el incremento observado en los valores energéticos de las proteínas observado en el periodo noviembre-enero (invernal) podría ser interpretado como el desarrollo de un proceso de gametogénesis activa, puesto que Villalba (1995) y Cáceres-Martínez y Figueras (1998) observaron un alto porcentaje de ejemplares en este estado de su ciclo reproductivo en las Rías de Arosa y Vigo. En cambio, la disminución en la energía contenida en carbohidratos y lípidos estaría probablemente relacionada con la escasa disponibilidad del alimento fitoplanctónico observada durante el lapso de noviembre a enero (fig. 1b). Esto último concuerda con los resultados de Zandee et al. (1980) y Okumus y Stirling (1998), autores que también observaron una disminución en los contenidos de carbohidratos y lípidos en el mejillón M. edulis durante el período invernal.

En cambio, el aumento de los valores energéticos de carbohidratos y lípidos durante lo que se podría considerar como un período de transición entre la estación invernal y la primaveral, probablemente se deba al aumento en la disponibilidad de 
groups. These decreases in both components suggest the spawning process; in the same period of the year, Villalba (1995) and Cáceres-Martínez and Figueras (1998) observed an increase in the percentage of specimens of $M$. galloprovincialis in a post-spawning state in the Arousa and Vigo Rias, respectively. Also, considerable decreases in lipid content resulting from spawning were also observed in natural populations of the mussels Mytilus platensis (De Moreno et al., 1980), M. edulis (Zandee et al., 1980) and M. galloprovincialis (Bressan and Marin, 1985; Da Ros et al., 1985; Ferrán et al., 1990); in the oysters Crassostrea virginica (Chu et al., 1990) and C. gigas (Berthelin et al., 2000); in the pectinids Pecten maximus (Besnard et al., 1989; Pazos et al., 1997) and Argopecten purpuratus (Martínez, 1991); and in the clam Glycymeris glycymeris (Galap et al., 1997).

Furthermore, a decrease in protein following spawning has been observed in the bivalves M. edulis (Zandee et al., 1980), M. galloprovincialis (Bressan and Marin, 1985), Argopecten irradians irradians (Epp et al., 1988), Ostrea edulis (Ruiz et al., 1992) and Crassostrea iridescens (Páez-Osuna et al., 1993).

With respect to the influence of the various environmental parameters and seed origin on the trends of the protein, carbohydrate, lipid and organic material energy values, several interesting features can be highlighted. From the start of the experiment to the beginning of January (days 1-37), the multiple regression analysis showed that seed origin had a significant influence on the variance observed in the energy content of the proteins, carbohydrates and lipids. It is worth emphasizing that the energy contribution of carbohydrates and lipids was lower in the rocky shore mussels (negative coefficient). This agrees with studies in which a decrease of carbohydrate and/or lipid reserves in rocky shore mussels subject to frequent periods of air exposure (Bayne et al., 1982; Gabbott, 1983; De Zwaan and Mathieu, 1992) was observed. Moreover, the mussel origin term continued to participate significantly in the explanation of the variance of the lipid energy content during the transitional period (days 50-110). In this case, however, the coefficient was positive, thus demonstrating that mussels of rocky shore origin were able to accumulate more lipid energy than subtidal mussels.

This regression model changes after spring because the mussel origin did not participate in the explanation of the variance of any of the different integrals of the biochemical compositions. However, at this point, TPM and chlorophyll $a$ / POM together explained percentages of variance greater than $38.0 \%, 38.5 \%, 55.8 \%$ and $55.8 \%$ in the protein, carbohydrate, lipid and organic material energy contribution, respectively. The positive coefficients suggest that energy acquisition in this period depends on these environmental parameters. Similar increments in total energy as a result of the high availability of food of phytoplanktonic origin have been observed in the oyster Ostrea puelchana (Fernández and de Vido, 1987) and O. edulis (Ruiz et al., 1992). alimento de origen fitoplanctónico (fig. 1b), aunque no se descarta un proceso paralelo de acumulación de reservas lipídicas en los gametos. En este sentido, Villalba (1995) y Cáceres-Martínez y Figueras (1998) observaron un alto porcentaje de ejemplares en proceso de maduración de gametos entre los meses de enero y abril. Este proceso de acumulación de reservas lipídicas fue observado previamente por Lubet et al. $(1983,1986)$ en el mejillón M. galloprovincialis durante su proceso de maduración de ovocitos.

A partir del mes de abril se observó una disminución de los equivalentes energéticos de proteínas y lípidos en ambos grupos de mejillones debido probablemente a un proceso de desove. Villalba (1995) y Cáceres-Martínez y Figueras (1998) observaron un aumento en el porcentaje de ejemplares desovados de M. galloprovincialis en las Rías de Arosa y Vigo durante el mismo periodo del año. Asimismo, se han mostrado disminuciones importantes en el contenido de lípidos como resultado de un proceso de desove, también observadas en poblaciones naturales de mejillones Mytilus platensis (De Moreno et al., 1980), M. edulis (Zandee et al., 1980) y M. galloprovincialis (Bressan y Marin, 1985; Da Ros et al., 1985; Ferrán et al., 1990), de las ostras Crassostrea virginica (Chu et al., 1990) y C. gigas (Berthelin et al., 2000), de pectínidos Pecten maximus (Besnard et al., 1989; Pazos et al., 1997) y Argopecten purpuratus (Martínez, 1991), y en la almeja Glycymeris glycymeris (Galap et al., 1997).

También se han reportado disminuciones en el contenido de proteínas, atribuidas al desove, en los bivalvos M. edulis (Zandee et al., 1980), M. galloprovincialis (Bressan y Marin, 1985), Argopecten irradians irradians (Epp et al., 1988), Ostrea edulis (Ruiz et al., 1992) y Crassostrea iridescens (Páez-Osuna et al., 1993).

Con respecto a la influencia de las variables ambientales y el origen de los mejillones sobre los cambios observados en los equivalentes energéticos de proteínas, carbohidratos, lípidos y materia orgánica se pueden puntualizar los siguientes aspectos: en los primeros 37 días ocurridos entre el inicio del experimento y principios de enero, el análisis de regresión múltiple mostró que el origen de los mejillones tuvo una influencia significativa sobre la varianza observada en los contenidos energéticos de proteínas, carbohidratos y lípidos. Además, los contenidos energéticos de carbohidratos y lípidos fueron más bajos en los mejillones intermareales, tal y como lo indica su coeficiente negativo (tabla 3). Esto concuerda con otros estudios sobre mejillones intermareales afectados por frecuentes periodos de exposición al aire (Bayne et al., 1982; Gabbott, 1983; De Zwaan y Mathieu, 1992).

Durante el periodo transicional (50-110 días del periodo experimental) el origen de los mejillones sigue contribuyendo a la explicación de la varianza de la energía contenida en los lípidos; no obstante en este caso los mejillones de origen intermareal tendrían una mayor acumulación de energía en los lípidos que la de los mejillones de origen submareal (a juzgar por el coeficiente positivo, tabla 4). 


\section{Acknowledgements}

The authors would like to thank Ana Ayala, Beatriz González, Lourdes Nieto and Sonia Villar for their technical assistance in the biochemical analyses; Juan Maneiro (Centro de Control de la Calidad del Medio Marino de la Consejería de Pesca, Marisqueo y Acuicultura, Xunta de Galicia) for the data of the environmental variables; and the crew of the José Maria Navaz from the Instituto Español de Oceanografía. This study was financed by the project CICYT REN2001-0501/MAR. Luis Freites was supported by a grant from the Consejo Nacional de Investigaciones Científicas y Tecnológicas (CONICIT), Venezuela.

\section{References}

Bayne, B.L. (1973). Aspects of the metabolism of Mytilus edulis during starvation. Neth. J. Sea Res., 7: 399-410.

Bayne, B.L. (1976). Aspects of reproduction in bivalve mollusc. In: M. Willey (ed.), Estuarine Processes, Academic Press, London, Vol. 1, pp. 432-448.

Bayne, B.L., Bubel, A., Gabbott, P.A., Livingstone, D.R., Lowe, D.M. and Moore, M.N. (1982). Glycogen utilization and gametogenesis in Mytilus edulis (L.). Mar. Biol. Lett., 1: 89-105.

Berthelin, C., Kellner, K. and Mathieu, M. (2000). Storage metabolism in the Pacific oyster Crassostrea gigas in relation to summer mortalities and reproductive cycle (west coast of France). Comp. Biochem. Physiol., 125B: 359-369.

Besnard, J.Y., Lubet, P. and Nouvelot, A. (1989). Seasonal variations of the fatty acid content of the neutral lipids and phospholipids in the female gonad of Pecten maximus L. Comp. Biochem. Physiol., 93B: 21-26.

Bressan, M. and Marin, G. (1985). Seasonal variation in biochemical composition and condition index of culture mussels (Mytilus galloprovincialis, Lmk.) in Venice Lagoon (North Adriatic). Aquaculture, 48: 13-21.

Beukema, J.J. and De Bruin, W. (1979). Calorific values of the soft parts of tellinid bivalve Macoma baltica (L.) as determined by two methods. J. Exp. Mar. Bio. Ecol., 37: 19-30.

Cáceres-Martínez, J. and Figueras, A. (1998). Long-term survey on wild and culture mussels (Mytilus galloprovincialis Lmk.) reproductive cycles in the Ria de Vigo (NW Spain). Aquaculture, 162: 141-156.

Chu, F.E., Webb, K.L. and Chen, J. (1990). Seasonal changes of lipids and fatty acids in oyster tissues (Crassostrea virginica) and estuarine particulate matter. Comp. Biochem. Physiol., 95B: 385-391.

Da Ros, L., Bressan, M. and Marin, M.G. (1985). Reproductive cycle of the mussel (Mytilus galloprovincialis, Lmk.) in Venice Lagoon (North Adriatic). Boll. Zoolog., 52: 223-229.

De Moreno, J.E.A., Pollero, R.J., Moreno, V.J. and Brenner, R.R. (1980). Lipids and fatty acids of the mussel (Mytilus platensis d'Orbigny) from South Atlantic waters. J. Exp. Mar. Bio. Ecol., 48: 263-276.

De Zwaan, A. and Mathieu, M. (1992). Cellular biochemistry and endocrinology. In: E. Gosling (ed.), The mussel Mytilus: Ecology, Physiology, Genetics and Culture. Elsevier, Amsterdan, pp.

223-307.

Epp, J., Bricelj, M.V. and Malouf, R.E. (1988). Seasonal partitioning and utilisation of energy reserves in two age classes of the bay scallop Argopecten irradians (Lamarck). J. Exp. Mar. Bio. Ecol., 121: 113-136.
Este modelo cambia a partir del periodo primavera-verano, debido a que el origen de los mejillones no contribuye a la explicación de la varianza de ninguno de los diferentes componentes bioquímicos, mientras que la MPT y la razón clorofila $a / \mathrm{MPO}$ explican, de manera conjunta, altos porcentajes de la varianza ocurrida en la energía contenida en proteínas, carbohidratos, lípidos y materia orgánica $(>38.0 \%, 38.5 \%$, $55.8 \%$ y $55.8 \%$, respectivamente), siendo sus coeficientes positivos, lo que sugiere que esta energía probablemente provenga de la obtenida de estas variables ambientales. Se han observado incrementos similares en los valores energéticos totales de las ostras Ostrea puelchana (Fernández y de Vido, 1987) y O. edulis (Ruíz et al., 1992), como resultado de una alta disponibilidad de alimento de origen fitoplanctónico.

\section{Agradecimientos}

Los autores agradecen a Ana Ayala, Beatriz González, Lourdes Nieto y Sonia Villar su asistencia técnica en los análisis bioquímicos. También agradecemos a Juan Maneiro, del Centro de Control de la Calidad del Medio Marino de la Consejería de Pesca, Marisqueo y Acuicultura (Xunta de Galicia), los datos de las variables ambientales, y a la tripulación del barco José María Navaez del Instituto Español de Oceanografía. Este estudio fue financiado por el proyecto CICYT MAR97 - 0592. Luis Freites disfruta de una beca de estudios financiada por el Consejo Nacional de Investigaciones Científicas y Tecnológicas de Venezuela (CONICIT).

Traducido al español por los autores.

Fernández, N. and de Vido, N. (1987). Biochemical composition, condition index, and energy value of Ostrea puelchana (D'Orbigny): Relationships with the reproductive cycle. J. Exp. Mar. Biol. Ecol., 108: 113-126.

Fernández-Reiriz, M.J., Labarta, U. and Babarro, J.M.F. (1996). Comparative allometries in growth and chemical composition of mussel (Mytilus galloprovincialis, Lmk.) cultured in two zones in the Ría Sada (Galicia, NW Spain). J. Shellfish Res., 15: 349-353.

Fernández-Reiriz, M.J., Labarta, U., Albentosa, M. and PérezCamacho, A. (1998). Effect of microalgal diets and commercial wheatgerm flours on the lipid profile of Ruditapes decussatus spat. Comp. Biochem. Physiol., 119: 369-377.

Ferrán, E., Treviño, M., Mancebo, M.J., Crespo, C. and Espinosa, J. (1990). Estudio del ciclo gonadal anual en Mytilus galloprovincialis: Cinética de poblaciones celulares en el manto y reservas bioenergéticas. Actas del III Congreso Nacional de Acuicultura, pp. 467-472.

Freites, L., Labarta, U. and Fernández-Reiriz, M.J. (2002a). Evolutions of the fatty acid profiles of sub-tidal and rocky shore mussel seed (Mytilus galloprovincialis Lmk). Influence of environmental parameters. J. Exp. Mar. Biol. Ecol., 268: 185-204.

Freites, L. Fernández-Reiriz, M.J. and Labarta, U. (2002b). Lipid classes of mussel seeds Mytilus galloprovincialis of subtidal and rocky shore origin. Aquaculture, 207(1-2): 97-116.

Gabbott, P.A. (1983). Developmental and seasonal metabolic activities in marine mollusca. In: K.M. Wilbur (ed.), The 
Mollusca. Environmental Biochemistry and Physiology. Academic Press, New York, Vol. 2, pp. 165-219.

Gabbott, P.A. and Bayne, B.L. (1973). Biochemical effects of temperature and nutritive stress on Mytilus edulis. J. Mar. Biol. Assoc. UK, 53: 269-286.

Gäde, G. (1975). Anaerobic metabolism of the common cockle, Cardium edule. I. The utilization of glycogen and accumulation of multiple end products. Arch. Intern. Physiol. Biochem., 83: 879-886.

Galap, C., Leboulenger, F. and Grillot, J.P. (1997). Seasonal variations in biochemical constituents during the reproductive cycle of the female dog cockle Glycymeris glycymeris. Mar. Biol., 129: 625-634.

Hummel, H., De Wolf, L., Zurburg, W., Apon, L., Bogaards, R.H. and Van Ruttenburg, M. (1989). The glycogen content in stressed marine bivalves: The initial absence of a decrease. Comp. Biochem. Physiol., 94B: 729-733.

Kluytmans, J.H., Zandee, D.I., Zurburg, W. and Pieters, H. (1980). The influence of seasonal changes on energy metabolism in Mytilus edulis (L.). III. Anaerobic energy metabolism. Comp. Biochem. Physiol., 67B: 307-315.

Lowry, O.H., Rosebrough, N.J. and Fair, A.L. (1951). Protein measurement with the folin phenol reagent. J. Biol. Chem., 193: 265-275.

Lubet, P., Gimazane, J.P. and Prunus, G. (1983). Cycle de reproduction de Mytilus galloprovincialis a la limite de son aire de répartition géographique. Haliotis, 11: 157-170.

Lubet, P., Brichon, G., Besnard, J.Y. and Zwingelstein, G. (1986). Sexual differences in the composition and metabolism of lipids in the mantle of the mussel Mytilus galloprovincialis Lmk. (Mollusca: Bivalvia). Comp. Biochem. Physiol., 84B: 279-285.

Martínez, G. (1991). Seasonal variation in biochemical composition of three size classes of the Chilean scallop Argopecten purpuratus (Lamarck, 1819). Veliger, 34: 335-343.

Napolitano, G.E., MacDonald, B.A., Thompson, R.J. and Ackman, R. G. (1992). Lipids composition of eggs and adductor muscle in giant scallops Placopecten magellanicus from different habitats. Mar. Biol., 113: 71-72.

Okumus, I. and Stirling, H.P. (1998). Seasonal variations in the weight, condition index and biochemical composition of mussels (Mytilus edulis L.) in suspended culture in two Scottish sea lochs. Aquaculture, 159: 249-261.

Páez-Osuna, F., Zazagueta-Padilla, H.M. and Osuna-López, J.I. (1993). Biochemical composition of the oysters Crassostrea iridescens (Hanley) and Crassostrea cortezienzis (Hertlein) in the northwest coast of Mexico: Seasonal changes. J. Exp. Mar. Biol. Ecol., 170: 1-9.

Pazos, A.J., Román, G., Acosta, C.P., Abad, M. and Sánchez, J.L. (1997). Influence of the gametogenic cycle on the biochemical composition of the ovary of the great scallop. Special Issue of the Scallop Workshop. Aquacult. Int., 4: 201-213.
Pérez-Camacho, A., Labarta, U. and Beiras, R. (1995). Growth of mussels (Mytilus galloprovincialis) on cultivation rafts: Influence of seed source, cultivation site and phytoplankton availability. Aquaculture, 138: 349-362.

Pieters, H., Kluytmans, J.H., Zurburg, W. and Zandee, D.I. (1979). The influence of seasonal changes on energy metabolism in Mytilus edulis L. I. Growth rate and biochemical composition in relation to environmental parameters and spawning. In: E. Naylor and R.G. Hartnoll (eds.), Cyclic Phenomena in Marine Plants and Animals. Pergamon Press, New York, pp. 285-292.

Pieters, H., Kluytmans, J.H., Zandee, D.I. and Cadee, G.C. (1980). Tissue composition and reproduction of Mytilus edulis dependent on food availability. Neth. J. Sea Res., 14: 349-361.

Riley, R.T. (1976). Changes in the total protein, lipid, carbohydrate, and extra-cellular body fluid free amino acids of the Pacific oyster Crassostrea gigas, during starvation. Proc. Nat. Shellfish Assoc., 65: 84-90.

Rodhouse, P.G., Roden, C.M., Burnell, G.M., Hensey, M.P., McMahon, T., Ottway B. and Ryan, T.H. (1984). Food resource, gametogenesis and growth of Mytilus edulis on the shore and in suspended culture: Killary Harbour, Ireland. J. Mar. Biol. Assoc. UK, 64: 513-529.

Rouser, G., Kritchevsky, G. y Yamamoto, A. (1967). Column chromatographic and associated procedures for separation and determination of phosphatides and glicolipids. In: G. Marinetti (ed.), Lipids Chromatographic Analysis. Marcel Dekker, New York, N. Y., pp. 99-163.

Ruiz, C., Martínez, D., Mosquera, G., Abad, M. and Sánchez, J.L. (1992). Seasonal variations in condition, reproductive activity and biochemical composition of the flat oyster, Ostrea edulis, from San Cibran (Galicia, Spain). Mar. Biol., 112: 67-74.

Strickland, J.D. and Parsons, T.R. (1968). A Practical Handbook of Seawater Analysis. Bull. Fish. Res. Board Canada, 311 pp.

Villalba, A. (1995). Gametogenic cycle of culture mussel, Mytilus galloprovincialis, in the bays of Galicia (NW Spain). Aquaculture, 130: 269-277.

Whyte, J.N.C., Englar, J.R. and Carswell, B.L. (1990). Biochemical composition and energy reserves in Crassostrea gigas exposed to different levels of nutrition. Aquaculture, 90: 157-172.

Zandee, D.I., Kluytmans, J.H., Zurburg, W. and Pieters, H. (1980). Seasonal variations in biochemical composition of Mytilus edulis (L.) with reference to energy metabolism and gametogenesis. Neth. J. Sea Res., 14: 1-29.

Zar, J.H. (1984) Biostatistical Analysis. 2nd ed. Prentice Hall, Englewood, New Jersey.

Zurburg, W., Kluytmans, J.H., Pieters, H. and Zandee, D.I. (1979). The influence of seasonal changes on energy metabolism in Mytilus edulis (L.). II. Organ specificity. In: E. Naylor and R.G. Hartnoll (eds.), Cyclic Phenomena in Marine Plants and Animals. Pergamon Press, New York, pp. 293-300. 